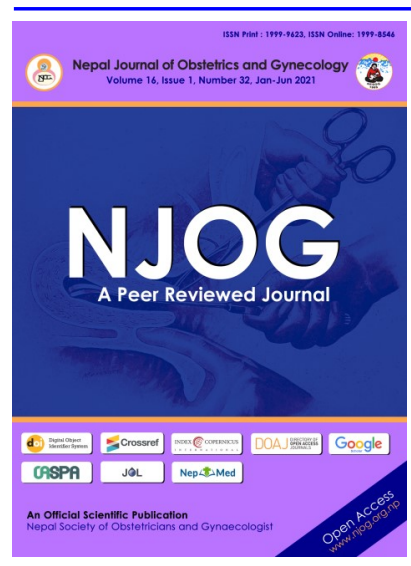

CORRESPONDENCE

Dr Babita Chaudhary

Department of OBGYN, Shree Birendra Hospital, Chhauni, Kathmandu, Nepal

Email:

babitachaudhary 2048

@gmail.com;

Phone: +977-9844611664

Received: November 29, 2020

Accepted: May 1, 2021

\section{Citation:}

Chaudhary B, Neupane B, Bam S. Quintuplet Pregnancy in a women with HIV positive status. Nep J Obstet Gynecol. 2021;16 (32):132-133. DOI: https:// doi.org/10.3126/ njog.v16i1.37622

\title{
Quintuplet Pregnancy in a women with HIV positive status
}

Babita Chaudhary, Bibhushan Neupane, Shiba Bam

Shree Birendra Hospital, Chhauni, Kathmandu, Nepal

\section{ABSTRACT}

Quintuplets are a rare occurrence and even rarer if they are born to a woman without fertility treatment. It is associated with not only high rates of obstetric complications but also increased perinatal morbidity and mortality. We here report a case of a woman with HIV positive status under ART with Quintuplets who delivered on her second trimester.

Keywords: fetal outcome; maternal outcome; quintuplet.

\section{INTRODUCTION}

Quintuplets are a set of five babies born to one mother at one birth. A baby that is part of such a set is called a quintuplet and sometimes referred to as a "quint." Though quintuplets and other higherorder multiple births (also known as super twins) are rare, the increased use of fertility drugs and assisted reproduction techniques have also brought an increase in these special types of pregnancies. Quintuplets can be fraternal (polyzygotic), identical (monozygotic), or a combination of both. Quintuplets can be all male, all female, or a combination of both, but monozygotic quintuplets will always be of the same sex. The spontaneous conception of quintuplets is extremely rare; the average estimate is 1 in over 60 million births. Most recent quintuplet births are the result of assisted reproductive techniques such as fertility-enhancing drugs or in vitro fertilization (IVF). ${ }^{1}$

\section{CASE}

A 30 years old HIV-positive Primigravida at 22 weeks 3 days of gestation with quintuplets presented with pain over lower abdomen and vaginal bleeding for 1 day. She was married for 8 years with primary subfertility and had conceived after one cycle of ovulation induction with clomiphene citrate. She was diagnos- ed to have quintuplet at 11 weeks of gestation by ultrasound but hadn't undergone fetal reduction. She had no family history of multiple pregnancy. She was booked case in our institution from 15 weeks of gestation. Her scan at 22 weeks of gestation revealed AFI $28.8 \mathrm{~cm}$ with fetuses weighing 425 573 grams. During her presentation in Emergency, she was anemic and was in active phase labour and delivered five fetuses ( 3 females and 2 males) along with five placentas on $6^{\text {th }}$ March 2020. [Table-1 and Figure-1]

Table-1: Details of quintuplet fetuses

\begin{tabular}{|c|c|c|c|c|}
\hline 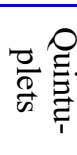 & $\underset{\mathscr{X}}{\mathscr{X}}$ & 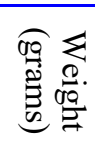 & 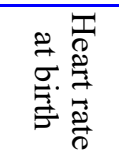 & 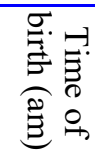 \\
\hline $1 \mathrm{st}$ & $\mathrm{F}$ & 430 & Absent & $00: 37$ \\
\hline 2nd & $\mathrm{F}$ & 590 & $<60$ & $1: 00$ \\
\hline $3 \mathrm{rd}$ & $\mathrm{F}$ & 460 & $<60$ & $08: 38$ \\
\hline 4th & $\mathrm{M}$ & 400 & Absent & $8: 50$ \\
\hline 5 th & $\mathrm{M}$ & 430 & Absent & $9: 10$ \\
\hline
\end{tabular}

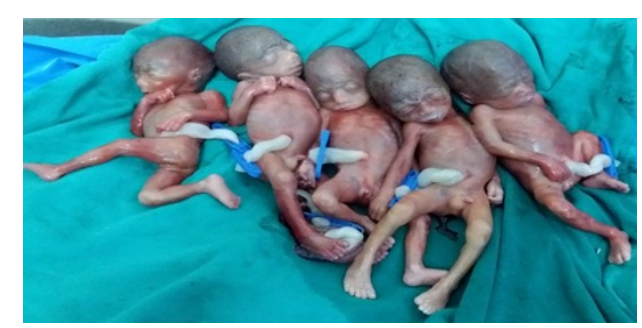

Figure-1: Quintuplets delivered

\section{COMMENTS}

Quintuplets are a rare occurrence, a natural wonder when they happen without any assisted reproductive technologies. Quintuplet pregnancies are associated with high rates of obstetric complications and significant perinatal morbidity and mortality. ${ }^{2}$ 
Before the advent of fertility drugs, triplets were rare, and quadruplets and quintuplets were almost never heard of. The spontaneous pregnancy rate for quintuplet gestation has been estimated as 1 in $65,610,000$ pregnancies by Hellin's law. With assisted reproductive technologies, these now have become common to an extent, thus raising concern about obstetric implications in such cases. The chance of identical quintuplets being born, as in the case of the Canadian Dionne sisters, is 1 in 57 million. The rate of quintuplets studied in Japan over a 12-year period was estimated to be approximately 0.77 per million births. $^{3}$

Higher order pregnancies needs a multidisciplinary approach for safe transition of a pregnant woman to motherhood. Not only Obstetrician but early involvement of radiologists, neonatologists and anesthesiologists for the assessment of such cases is essential for a successful obstetrical outcome.

Maternal complications such as hyperemesis gravidarum, pre-eclampsia, gestational diabetes mellitus, cardiopulmonary embarrassment, abruptio placentae, incompetent cervix and preterm labour are well documented. ${ }^{4}$ Perinatal complications such as congenital anomalies, prematurity, respiratory distress syndrome, perinatal mortality, twin to twin transfusion syndrome, intraventricular hemorrhage may be present. $^{5}$

Though the first quintuplets known to have survived infancy are the Dionne quintuplets born May 28, 1934, in Corbeil, Ontario, Canada the world record for surviving quintuplet was previously recorded to be 55 days which was one of five babies born to a mother in Lisbon, Portugal, in $1866 .{ }^{6}$ Other well followed-up and well-described quintuplets include the Whalen quintuplets and the Brooks quintuplets. ${ }^{7}$

In a case series by Schenker et al on five quintuplet pregnancies, three delivered by cesarean section at 33 to 35 weeks gestation, of the 15 children born, 13 survived. ${ }^{8}$ In the largest case series on 36 quintuplet pregnancy by Francois et al, five pregnancies occurred after ovulation induction and hormonal stimulation while 31 resulted from assisted reproductive technologies. In our case, the patient had received one cycle of ovulation induction which resulted to quintuplet pregnancies.

Multiple pregnancy continues to carry a high risk, and women with multiple pregnancies should be offered extra care during the antenatal period with the focus on early identification and timely treatment of complications. ${ }^{9}$ Specifically with reference to preterm labor, surveillance for signs and symptoms should be undertaken at earlier gestational ages than would be expected for other pregnancies. $^{2}$

In our case, the patient didn't seek proper initial antenatal check-ups in a tertiary setting hospital. And also being a HIV positive case she was not accepted for fetal reduction during her $1^{\text {st }}$ trimester because of the social taboo existing in a developing country like ours for patients with HIV. Had she been given a proper antenatal check-up, the couple would not have suffered such a loss.

\section{CONCLUSIONS}

The risks of multifetal pregnancies are significant. Counseling of couples seeking treatment for infertility is required to make aware of the potential complications like multiple pregnancies.

\section{REFERENCES}

1. Kaur HK, Sharma S, Bedi M, Jindal P. Spontaneously Conceived Quintuplets Pregnancy: A Rare Case Report. Schol J Med Case. 2017; 5 (8): 514-6.

2. Francois K, Alperin A, Elliot JP. Outcomes of Quintuplet Pregnancies. J Reprod Med. 2001;46:1047-51.

3. Imaizumi Y. Triplets and higher order multiple births in Japan. Acta Geneticia Medicare et Gemellolgiae. 1990;39:295-306.

4. Umeora OU, Aneziokoro EA, Egwuatu VE. Higher Order Multiple births in Abakaliki Southeast Nigeria. Singapore Med J. 2011;52 (3):163-7.

5. Nkyekyer K. Multiple Pregnancy : Comprehensive Obstetrics in the Tropics. Accra: Asante Hittscher. 2002;1:162-72.

6. Mahrukh F, Pashtoon MK, Rabeea R, Shahnaz NB. Quintuplets born to a woman without fertility treatment in Pakistan. Fertil Steril. 2008;90(5).

7. Margeret S. The Brooks Quintuplets Turn Two! KC Parent 2009 March 15; [cited 20215 10]. Available from: https://kcparent.com/parenting/ the-brooks-quintuplets-turn-two/.

8. Schenker JG, Laufer N, Weinstein D, Yarkoni S. Quintuplet Pregnancies. Eur J Obstet Gynecol Reprod Biol. 1980;1:257-68.

9. Babay ZA, Addar MH, Al-Meshari AA. Multiple Pregnancy Management: The King Khalid Hospital Experience. Saudi Med. 1994;14:4068. 